\title{
Nova combinação em Colaconema (Colaconematales, Rhodophyta) e adição à flora de macroalgas marinhas do Nordeste do Brasil
} New combination in Colaconema (Colaconematales, Rhodophyta),
addition to marine algae from Northeastern of Brazil

\author{
Alana Araujo dos Santos ${ }^{1,2}$ \& Carlos Wallace do Nascimento Moura ${ }^{1}$
}

\begin{abstract}
Resumo
A partir do estudo de epífitas de Acetabularia crenulata ocorrentes na Ilha de Itaparica, Bahia, Brasil, foram coletados espécimes do gênero Colaconema, os quais foram identificados como Colaconema hypneae (Börgesen) comb. nov., a partir de Acrochaetium hypneae (Börgesen) Börgesen. Esta proposição nomenclatural baseiase na morfologia do plasto, caráter diacrítico em nível de gênero. São apresentadas descrição, ilustrações, comparações com táxons afins e ampliada a distribuição geográfica do táxon ao litoral costeiro do Nordeste do Brasil.
\end{abstract}

Palavras-chave: cloroplasto, Colaconemataceae, epífita, nordeste, Taxonomia.

\begin{abstract}
During a study on epiphyte algae of Acetabularia crenulata from Itaparica Island, Bahia, Brazil, specimens of the genus Colaconema were collected and identified as Colaconema hypneae (Börgesen) comb. nov., which previously was considered Acrochaetium hypneae (Börgesen) Börgesen. This nomenclatural proposal is based on plastids morphology, distinctive character of the genus. Description, illustrations, comparisons among related taxa are presented, as well as the extension of its geographic distribution to the northeastern coast of Brazil.
\end{abstract}

Key words: Colaconemataceae, epiphyte, northeastern, plastid, Taxonomy.

\section{Introdução}

As algas acrochaetióides compreendem um grupo de algas microscópicas, de hábito heterótrico, fixas ao substrato por uma única célula ou por um sistema prostrado multicelular, dos quais partem filamentos unisseriados, eretos, simples a ramificados, com células cilíndricas, contendo plastos de forma e número variáveis (Woelkerling 1983). A reprodução assexuada, através de monosporângios, é a forma mais comum de reprodução neste grupo, embora a presença de bisporângios, tetrasporângios e reprodução sexuada (formação de espermatângios e carpogônios) tenham sido referidas para algumas espécies (Rosenvinge 1909; Hamel 1927;
Woelkerling 1973; Ugadim 1974). Devido à simplicidade do talo das algas acrochaetióides, a taxonomia do grupo é bastante complexa (Woelkerling 1983).

Taylor (1960), baseado na forma e posição dos cloroplastos, reconheceu quatro gêneros em Acrochaetiaceae: Rhodochorton Nägeli, Kylinia Rosenv., Acrochaetium Nägeli e Audouinella Bory. Woelkerling (1971) estudando as espécies do sul da Austrália, transferiu as espécies-tipo de Acrochaetium e Rhodochorton para o gênero Audouinella e referiu este como "complexo Audouinella". O autor reconheceu apenas dois gêneros de Acrochaetiaceae: Audouinella, com plasto único, parietal a estrelado, e Colaconema Batters,

${ }^{1}$ Universidade Estadual de Feira de Santana, Depto. Ciências Biológicas, Programa de Pós-Graduação em Botânica, Laboratório de Ficologia, Av. Transnordestina s/n, 44036-900, Novo Horizonte, Feira de Santana, BA, Brasil.

${ }^{2}$ Autor para correspondência: araujo.alana@gmail.com. 
com muitos plastos, com ou sem pirenóide. Este posicionamento foi seguido por alguns autores, como Schneider (1983) e Schneider \& Searles (1991).

Recentemente, Harper \& Saunders (2002), baseados em dados morfológicos e moleculares de Acrochaetiales, reconheceram duas ordens distintas: Acrochaetiales e Colaconematales. A partir da morfologia do plasto, característica considerada diagnóstica em nível de gênero, os autores reconheceram em Acrochaetiales os gêneros Rhodochorton (com células portando muitos plastos discóides a laminares, parietais, sem pirenóide), Audouinella (com células portando muitos plastos lobados a discóides, sem pirenóide) e Acrochaetium (com plasto único, estrelado, axial, com um pirenóide). Já em Colaconematales, reconheceram um único gênero, Colaconema, caracterizado por apresentar células com um a vários plastos parietais de formas variadas (laminares, lobados, espiralados, irregulares, nunca estrelados), com ou sem pirenóides. De acordo com Affonso-Carrillo et al. (2007), dentre as algas acrochaetióides o único gênero com plasto parietal laminar lobado, com um pirenóide, é Colaconema.

Atualmente, são reconhecidas 35 espécies de Colaconema, exclusivamente marinhas, com ampla distribuição pelas regiões tropicais e temperadas do globo. As espécies de Colaconema podem apresentar hábito epifítico, endofítico, epizóico, endozóico e, raramente, epilítico (Guiry \& Guiry 2010).

A partir do estudo de epífitas de Acetabularia crenulata J.V. Lamour ocorrentes na Ilha de Itaparica, Bahia, Brasil, foram observados espécimes do gênero Colaconema, os quais foram identificados como Colaconema hypneae (Börgesen) A.A. Santos \& C.W.N. Moura, uma nova combinação, espécie com registros escassos no litoral brasileiro. São apresentadas descrição, ilustrações, comparações com táxons afins e ampliada a distribuição geográfica do táxon ao litoral costeiro do Nordeste do Brasil.

\section{Material e Métodos}

Os espécimes estudados foram encontrados crescendo sobre Acetabularia crenulata, nas Praias da Barra Grande (12 $59^{\circ}$ S e $38^{\circ} 37^{\prime} \mathrm{W}$ ) e da Penha (13으'S e $\left.38^{\circ} 41^{\prime} \mathrm{W}\right)$, Ilha de Itaparica, Bahia, Brasil. Os talos de A. crenulata foram coletados com espátula, acondicionados em frascos de polietileno devidamente etiquetados e contendo água do mar. Em laboratório, parte dos espécimes de $A$. crenulata foi fixada em solução de formalina a $4 \%$ e alguns talos foram cultivados sob condições controladas.

Visando acompanhar o crescimento do talo de Colaconema hypneae, alguns talos de $A$. crenulata foram cultivados em frascos de vidro tipo "baby-food" contendo água do mar esterilizada e enriquecida com solução Von Stosch $\left(8 \mathrm{ml} . \mathrm{L}^{-1}\right)$ (Oliveira et al. 1995), com salinidade de 36 UPS, sendo o meio renovado semanalmente. Os espécimes foram mantidos em câmara de cultivo, à temperatura de $20 \pm 1^{\circ} \mathrm{C}$, irradiância de $65 \pm 5 \mu \mathrm{mol}$ de fótons. $\mathrm{m}^{-2} \cdot \mathrm{s}^{-1}$ fornecida por tubos de luz branca fria fluorescente, dispostos horizontalmente em relação aos recipientes, e fotoperíodo de 12:12h (claro:escuro) (Gestinari et al. 2005).

As características morfológicas e anatômicas de Colaconema hypneae foram analisadas com o auxílio de estereomicroscópio e microscópio fotônico (Carl Zeiss) acoplado com ocular micrométrica e máquina fotográfica (Sony CyberShot 7.0). As dimensões (diâmetro e comprimento) de cada estrutura foram estabelecidas através de 10 a 20 medidas feitas ao acaso. O aspecto geral da espécie foi obtido com máquina fotográfica digital (Sony CyberShot 7.0).

O sistema de classificação segue Wynne (2005) e as citações de autores seguem Brummit \& Powell (1992).

Após análise, os talos de Acetabularia crenulata (forófito) foram tombados em coleção líquida do Herbário da Universidade Estadual de Feira de Santana (HUEFS).

\section{Resultados e Discussão}

Colaconema hypneae (Börgesen) A.A.Santos \& C.W.N.Moura, comb. nov. Chantransia hypneae Börgesen. Bot. Tidsskr. 30: 2. 1909. Acrochaetium hypneae (Börgesen) Börgesen. Dansk Bot. Ark., p. 32, figs. 53-54. 1915. Audouinella hypneae (Börgesen) Lawson \& John., Nova Hedw. Beih., p. 172. 1982.

Localidade-tipo: Saint Thomas, Ilhas Virgens. Acrochaetium seriatum Börgesen. Dansk Bot. Ark., p. 51, figs. 25-28. 1915. Audouinella seriata (Börgesen) Garbary. Bot. Mar., p. 490. 1979. Colaconema seriata (Börgesen) Stegenga. S. Afr. J. B., p. 323, fig. 24. $1985 . \quad$ Fig. 1a-i

Talo microscópico, medindo até 1,6 mm altura, róseo-claro a escuro, fixo por sistema prostrado constituído por filamentos curtos de células poligonais a alongadas, (50)-121,5-(177,5) $\mu \mathrm{m}$ compr., que secundariamente formam um disco 
pseudoparenquimatoso, irregular, (140)-483(900) $\mu \mathrm{m}$ diâm., com esporo original persistente, ca. $20 \mu \mathrm{m}$ diâm. do qual partem filamentos unisseriados, eretos, com ramificação unilateral, alterna ou irregular, esparsa a densa; ramos com disposição unilateral, (200)-286-(350) $\mu \mathrm{m}$ compr., diminuindo em direção ao ápice do talo; ramos terminais retos, às vezes pendentes. Células

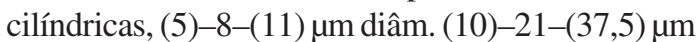
compr., afilando em direção ao ápice; células dos

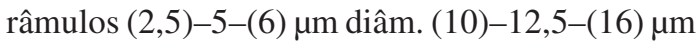
compr.; célula apical 2,5-5 $\mu \mathrm{m}$ diâm., ca. 47,5 $\mu \mathrm{m}$ compr. Cada célula com cloroplasto parietal, lobado, com pirenóide. Monosporângios ovais, sésseis ou pedunculados (1-2 células), (2,5)-7,5-

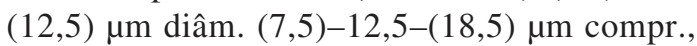
dispostos em série unilateral (3-8 esporos) na face adaxial, raro na abaxial, dos râmulos, às vezes, dos ramos; parede do monosporângio às vezes persistente. Foram observados esporos germinando na planta-mãe.

Material examinado: BRASIL. BAHIA: Ilha de Itaparica, Vera Cruz, Praia da Penha, 18.III.2007, C.W.N. Moura s.n. (HUEFS 130885); 19.V.2007, A.A. Santos s.n. (HUEFS 130886); 14.VII.2007, G.L. Alves \& G.J.R. Peixoto s.n. (HUEFS 130887); 27.IX.2007, A.A. Santos \& G.J.R. Peixoto s.n. (HUEFS 130888); 25.XI.2007, A.A. Santos \& G.L. Alves s.n. (HUEFS 130889); 23.I.2008, A.A. Santos s.n. (HUEFS 147558); 8.III.2008, A.A. Santos s.n. (HUEFS 147559). Praia da Barra Grande, 19.III.2007, A.A. Santos s.n. (HUEFS 147560); 18.V.2007, A.A. Santos s.n. (HUEFS 147561); 14.VII.2007, A.A. Santos s.n. (HUEFS 147562); 27.IX.2007, I.S. Oliveira \& I.B. Oliveira s.n. (HUEFS 130890); 25.XI.2007, A.M. Alves.\& G.J.P. Ramos s.n. (HUEFS 147563).

Distribuição geográfica no Atlântico Americano: Flórida; Texas; Geórgia; Carolina do Norte; Carolina do Sul; Bermudas; Ilhas Virgens; Venezuela; Brasil (Taylor 1960; Oliveira Filho \& Ugadim 1976; Schneider 1983; Ganesan 1989; Dawes \& Mathieson 2008).

O plasto do material de Colaconema hypneae estudado é similar ao descrito para o gênero por Harper \& Saunders (2002) e para a espécie por Börgesen (1915), Schneider (1983) e Schneider \& Searles (1991) (Fig. 1c).

Börgesen (1915) descreveu Colaconema hypneae (como Acrochaetium hypneae) juntamente com Acrochaetium seriatum, as quais diferiam apenas quanto à forma de fixação e hábito; A. seriatum apresentando disco basal prostrado, multicelular e hábito epifítico, $e C$. hypneae com filamentos prostrados, curtos e hábito endofítico.
Taylor (1960) também reconheceu as duas espécies (como Acrochaetium).

Schneider (1983) estudando as espécies de algas acrochaetióides da Carolina do Norte, transferiu algumas espécies posicionadas em Acrochaetium para Audouinella. Neste trabalho, o autor considerou Acrochaetium seriatum sinônimo de Colaconema hypneae (como Audouinella hypneae). Estas foram descritas como epifíticas, endofíticas ou epiendofíticas, com sistema prostrado inicialmente compacto, discóide ou filamentoso, podendo formar um disco pseudoparenquimatoso. $\mathrm{O}$ autor observou que este sistema de fixação variava no mesmo (Arthrocladia Duby) e em diferentes hospedeiros (diversas algas e conchas de animais) e atribuiu estas diferenças à textura do hospedeiro.

No presente estudo, observou-se a presença de diferentes padrões de fixação em Colaconema hypneae, desde filamentos curtos de células alongadas até a formação de discos pseudoparenquimatosos, irregulares (Figs. 1d-f).

Nos espécimes analisados, observou-se variação no padrão de ramificação do talo, algumas plantas apresentando ramificação esparsa, alterna a irregular (Fig. 1a), como nos exemplares referidos por Börgesen (1915, figs. 25A-B, 27, 54A), Abbott (1999, figs. 3J, como Acrochaetium seriatum) e Dawes \& Mathieson (2008, pr. 23, fig. 7, como A. hypneae), enquanto outras apresentaram talos densamente ramificados sem padrão definido, como nos exemplares observados em cultivo in vitro (Fig. 1b).

No Brasil, a espécie foi referida para o Estado do Rio de Janeiro (Oliveira-Filho 1977, como Acrochaetium hypneae e A. seriatum; Széchy \& Nassar 2005, como A. hypneae) e para o Atol das Rocas (Oliveira Filho \& Ugadim 1976, como A. seriatum). A partir deste trabalho, a espécie teve a sua distribuição ampliada para o litoral costeiro do nordeste brasileiro.

\section{Agradecimentos}

Ao CNPq (Conselho Nacional de Desenvolvimento Científico e Tecnológico) a concessão da bolsa de mestrado à primeira autora, à FAPESB (Proc. PPP 0011/2006), FAPESB-UFBAFAPEX (Proc. 049/2008), ao CNPq/FAPESB (Projeto Flora da Bahia), à UEFS (Universidade Estadual de Feira de Santana) o auxílio na realização das coletas. À Dra. Sílvia Maria Pita de Beauclair 


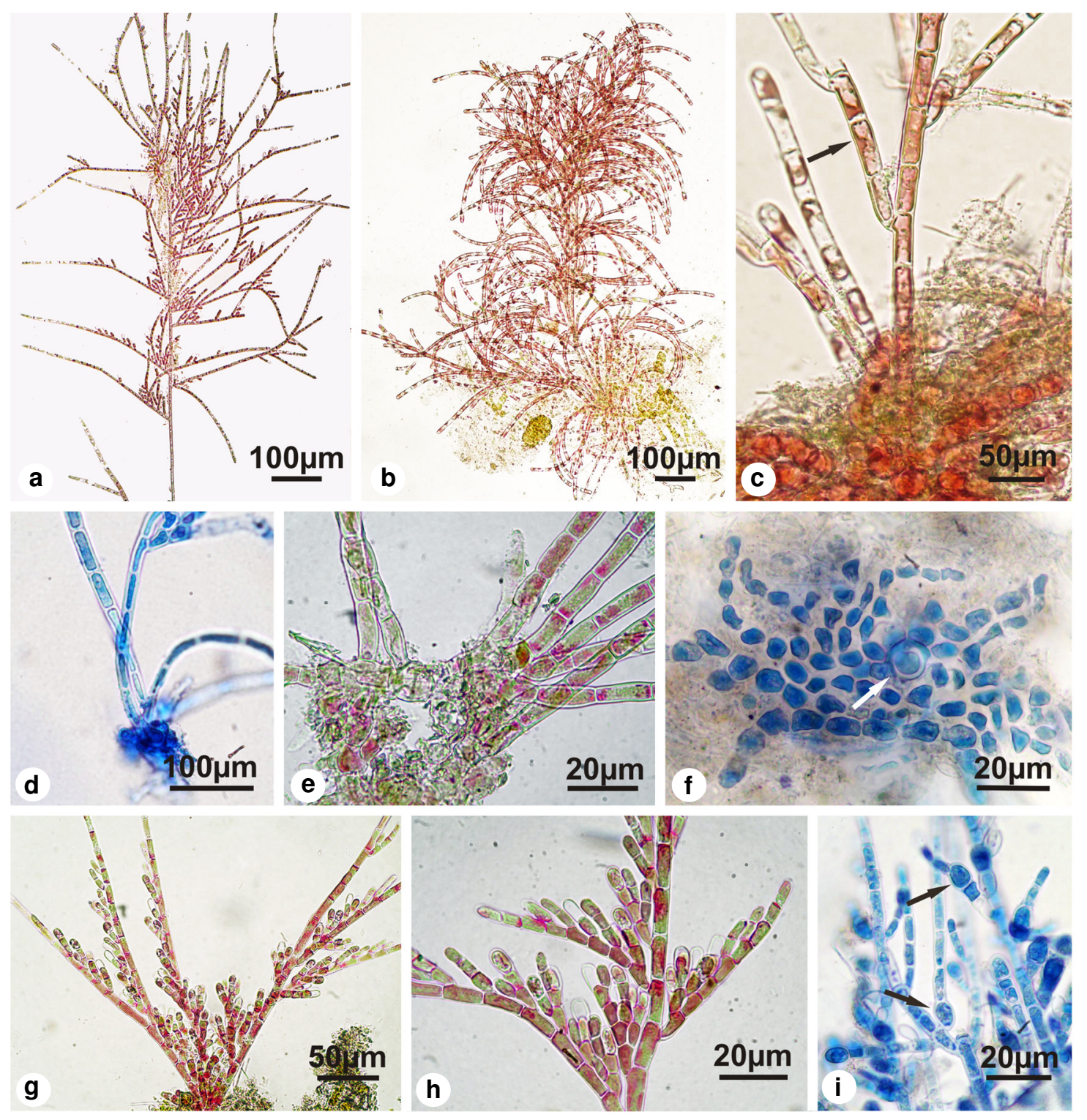

Figura 1 - Colaconema hypneae (Börgesen) A.A.Santos \& C.W.N.Moura - a. aspecto geral do talo com ramificação característica; b. talo densamente ramificado, proveniente de cultivo in vitro; c. células com cloroplasto parietal lobado (seta); d. detalhe de esporos persistentes originando eixos eretos; e. fixação do talo ao substrato por filamento de células prostradas; f. fixação do talo ao substrato por disco pseudoparenquimatoso, irregular, note a permanência do esporo persistente (seta); g. monosporângios dispostos em série unilateral (3-8 esporos) na face adaxial, às vezes na abaxial, dos râmulos; h. detalhe de monosporângios pedunculados, note parede persistente de alguns esporos; i. esporos germinando sobre a planta-mãe (setas).

Figure 1 - Colaconema hypneae (Börgesen) A.A.Santos \& C.W.N.Moura - a. general view of the thalus with characteristic ramification; b. densely branched thalus, from cultivation in vitro; c. cells with a lobed parietal plastid (arrow); d. detail of persistent spores originating upright axes; e. fixation of the thalus to the substrate by filaments of prostrate cells (arrows); f. fixation of the thalus to the substrate by a pseudoparenchymatous and irregular disk, note the permanence of persistent spore (arrow); g. monospores disposal in unilateral series (3-8 spores) at the adaxial side, sometimes at the abaxial, of the branchlets; h. detail of pedunculated monospores, note the persistent wall of some spores; i. spores germinating above the parental algae (arrows). 
Guimarães (Instituto de Botânica, SP), o auxílio na identificação de Colaconema e por disponibilizar sua bibliografia pessoal.

\section{Referências}

Abbott, I.A. 1999. Marine red algae of the Hawaiian Islands. Bishop Museum Press, Honolulu. 477p.

Affonso-Carrillo, J.; Sansón, M.; Sangil, C. \& Díaz-Villa, T. 2007. New records of benthic marine algae from the Canary Islands (eastern Atlantic Ocean): morphology, taxonomy and distribution. Botanica Marina 50: 119-127.

Börgesen, F. 1915. The marine algae of the Danish West Indies. Part III. Rhodophyceae (2) Dansk Botanisque Archives 3: 1-80.

Brummitt, R.K. \& Powell, C.E. 1992. Authors of plant names. Royal Botanic Gardens, Kew. 732p.

Dawes, C.J. \& Mathieson, A.C. 2008. The seaweeds of Florida. University Press of Florida, Gainesville. 591p.

Ganesan, E.K. 1989. A catalog of benthic marine algae and seagrass of Venezuela. Conicit Fondo Editorial, Caracas. 237p.

Gestinari, L.M.; Yoneshigue-Valentim, Y. \& Pereira, S.M.B. 2005. Influência da concentração de nutrientes e da aeração da água no desenvolvimento de Cladophora vagabunda (L.) C.Hoek (Chlorophyta, Cladophorales). In: Sociedade Brasileira de Ficologia (org.). X Reunião Brasileira de Ficologia, 2004. Formação de ficólogos: um compromisso com a sustentabilidade dos recursos aquáticos: anais... Museu Nacional, Rio de Janeiro, Série Livros 10: 275-288.

Guiry, M.D. \& Guiry, G.M. 2010. AlgaeBase. Worldwide electronic publication, national University of Ireland, Galway. Disponível em: <http:www. algaebase.org > Acesso em 28 maio 2010.

Hamel, G. 1927. Recherches sur les genres Acrochaetium Nägeli et Rhodochorton Naeg. Dissertation, Paris.

Harper, J.T. \& Saunders, G.W. 2002. A re-classification of the Acrochaetiales based on molecular and morphological data, and establishment of the Colaconematales ord. nov. (Florideophyceae, Rhodophyta). European Journal of Phycology 37: 463-476.

Oliveira-Filho, E.C. 1977. Algas marinhas bentônicas do Brasil. Tese de Livre-Docência. Universidade de São Paulo, São Paulo. 477p.

Oliveira-Filho, E.C. \& Ugadim, Y. 1976. A survey of the marine algae of Atol das Rocas (Brazil). Phycologia 15: 41-44.
Oliveira-Filho, E.C.; Paula, E.J.; Plastino, E.M. \& Petti, R. 1995. Manual de métodos ficológicos. In: Alveal, K.; Ferrario, M.E.; Oliveira, E.C. \& Sar, E. (eds.). Metodologias para cultivo no axénico de macroalgas marinas in vitro. Universidad de Concepción, Concepción. Pp. 429-447.

Rosenvinge, L.K. 1909. The marine algae of Denmark. I. Rhodophyceae 1. Kongelige Danske Vidensk - abernes Selskabs Skrifter, 7 Raekke, Naturvidenskabelig og Mathematisk afdeling 6:1-44.

Schneider, C.G. 1983. The red algal genus Audouinella Bory (Nemaliales: Acrochaetiaceae) from North Carolina. Smithsonian Contributions to the Marine Sciences 22: 1-25.

Schneider, C.W. \& Searles, R.B. 1991. Seaweeds of the Southeastern United States - Cape Hatteras to Cape Canaveral. Duke University Press, Durham and London. 553p.

Széchy, M.T.M. \& Nassar, C.A.G. 2005. Flora ficológica bentônicas da Baía da Ribeira, sul do estado do Rio de Janeiro: avaliação após duas décadas de operação da Central Nuclear In: Sociedade Brasileira de Ficologia (org.). X Reunião Brasileira de Ficologia, 2004. Formação de ficólogos: um compromisso com a sustentabilidade dos recursos aquáticos: anais... Museu Nacional, Rio de Janeiro, Série Livros 10: 373-397.

Taylor, W.R. 1960. Marine algae of the Eastern tropical and subtropical coasts of the Americas. Michigan Press, Michigan. 870p.

Ugadim, Y. 1974. Algas marinhas bentônicas do litoral sul do estado de São Paulo e do litoral do Paraná, III - Divisão Rhodophyta (1): Goniotrichales, Bangiales, Nemalionales e Gelidiales. Boletim de Botânica da Universidade de São Paulo 2: 93-137.

Woelkerling, W.M.J. 1971. Morphology and taxonomy of the Audouinella complex (Rhodophyta) in Southern Australia. Australian Journal of Botany, Suppl. Ser. 1: 1-91.

Woelkerling, W.M.J. 1973. The morphology and systematic of the Audouinella complex (Acrochaetiaceae, Rhodophyta) in Northeastern United States. Rhodora 75: 529-621.

Woelkerling, W.M.J. 1983. The Audouinella (AcrochaetiumRhodochorton) complex (Rhodophyta): present perspectives. Phycologia 22: 59-92

Wynne, M.J. 2005. A checklist of benthic marine algae of the tropical and subtropical western Atlantic: second revision. Nova Hedwigia 129: 1-152. 